\title{
Baby-Friendly Hospital Initiative: Situation in Nepal
}

${ }^{1} \mathrm{BPH} 17$ th and MPH 12th Batch, Maharajgunj Medical Campus, Institute of Medicine, TU, Nepal

\section{Background}

Right to nutrition including breast milk is the right of every child. (1) Breastfeeding is a natural process of feeding the newborns and isuniversally accepted as the best method of feeding babies. It helps to develop the foundation for a caring and trusting relationship between mother and child.

History suggests, during 20thcentury, significant increase of women's involvement in workplace outside the home setting had made breast-feeding less popular and a burden. (2) Urbanization and advances in technology had contributed further. With the rapid growth of industries and their competition in the twentieth century, industrial food products were developed along with the production of breast milk substitutes. (2)Decrease in breastfeeding prevalence was found toincrease the morbidity and mortality among children. $(3,4,5,6)$ This situation received the worldwide attention and to address the issue, Baby Friendly Hospital Initiative (BFHI)was initiated by WHO and UNICEF in 1991. (7)

BFHI is a global effort launched by WHO and UNICEF to implement practices that protect, promote and support breastfeeding. The initiative has two main goals: a) to transform hospitals and maternity facilities through implementation of the Ten Steps and b) to end the practice of distribution of free and low-cost supplies of breast milk substitutes to maternity wards and hospitals. BFHI has incorporated the International Code of Marketing of Breast-milk Substitutes (1981) and is aimed to protect and promote breastfeeding. Since thelaunch of initiative, more than 20,000 hospitals in 156 countries in the world have adopted it over the last 15 years. (7)

In 2002, Global Strategy for Infant and Young Child Feeding was developed by WHO and UNICEF which was based on the Innocenti Declaration and BHFI and addresses the needs of all children, including those living in difficult circumstances, such as mothers living with HIV, low birth-weight infants and infants in emergency situations.

In the process of development and expansion of the BFHI, several regional and national level meetings were organized for effective networking and providing feedback and recommendations. These meetings updated the global criteria, assessment tools and the training courses. (7) Inclusion of mother friendly care within the initiative was one of the important recommendations. Although the revision was done in 2004-2005, the final version of the materials was completed in 2007. (7)

\section{Global and Regional Scenario}

Asignificant progress has been observed in improving infantand young child feeding practices worldwide after the adoption of original Innocenti Declaration in 1990.However, inappropriate feeding practices,sub-optimal or no breastfeeding and inadequate complementary feeding has still remained the greatest threat to child health and survival globally. (8) Studies showed that improved breastfeeding alone could save the lives of more than 3,500 children every day, more than any other preventive intervention. (8) Promotion of breastfeeding has been identified as one of the important 45 evidence based interventions to address undernutrition in children. (9)

According to UNICEF, till 2002, 14,994 hospitals throughout the world were declared as baby friendly with highest number 8747 in the East and Pacific Region followed by South Asia Region. China is the country with largest numbers of baby friendly hospitals [6312] while India has the second largest number [1250]. (10)

There are some success stories of implementation of BFHI in different parts of the globe. Cuba, China, Gabon, Chile etc. have such examples. In Cuba, the rate of exclusive breastfeeding was increased almost three times from $25 \%$ to $72 \%$ in the six years' duration (1990-1996) where 49 out of 56 hospitals were identified as baby friendly. (10) In China which has more than 6,000 baby-friendly hospitals, exclusive breastfeeding in rural and urban areas rose significantly. It raised from 29 per cent in 1992 to 68 per cent in 1994 in rural areas while in urban areas; the increase was from 10 per cent to 48 percent. (10) Similarly, data from Central Hospital of Libreville in Gabon showed that cases of neonatal diarrhea fell by 15 per cent, diarrheal dehydration declined by 14 per cent and mortality fell by 8 per cent after successful implementation of BFHI. (8)

CORRESPONDENCE: Narayan Subedi, BPH 17th and MPH 12th Batch,Maharajgunj Medical Campus, Institute of Medicine, TU, Nepal. Email: subedi.narayan@gmail.com 


\section{National Scenario}

In Nepal BFHI activities were started in 1994 with the training of health workers from 22 hospitals all over the country till 1996. (11) After training, these hospitals were assessed by external and internal assessors in 1997-98 through Nepal Pediatric Society and seven of the hospitals were certified as Baby Friendly Hospitals. These seven hospitals are: Tribhuvan University Teaching Hospital, Maharajgunj, Kathmandu, Maternity Hospital, Thapathali, Kathmandu, Patan Hospital, Lalitpur, Bhaktapur Hospital, Bhaktapur, Hetauda Hospital, Makawanpur, BP Koirala Institute of Health Science, Dharan and Koshi Zonal Hospital, Bitratnagar. (11)

According to the last two Demographic Health Surveys (DHS $2006 \& 2011)$ there has not been any change in the neonatal mortality which is constant at 33/1000 live births. Practice of initiation of breastfeeding within one hour of birth was only $35 \%$ and exclusive breastfeeding for six months was $53 \%$ in 2006, (12) but there has been some increment in both the indicators in 2011. Early initiation of breastfeeding rose to $45 \%$ and exclusive breastfeeding to $70 \%$. (13) The reasons of such increment could be due to increase in literacy and awareness among the women.

Although there is a need of continuous monitoring and supervision of BFHI activities to ensure proper implementation, it was about 13 years that no any monitoring and assessment activities were carried out in Nepal. In 2011, an assessment was carried out in all of the 7 BFHI hospitals initiated by Child Health Division, Department of Health Services which used the revised tools developed by WHO/ UNICEF. (11) For the assessment,interview was done with Head of the Institutions, hospital staffs, pregnant women and lactating mothers and observation in different units of the hospitals, followed by a market survey.

The study drew some interesting findings. All the hospitals certified as BFHI were found not fulfilling all the 10 steps of BFHI activities. There was no display of policy on BFHI in the hospitals, health workers were very limited or were not trained, demand feeding was not strictly followed and mother support group or mother friendly care did not exist in any of these hospitals but these hospitals had good practice of rooming-in and pacifier and teats were not provided to newborns.Pre test counseling on HIV testing was not done for all pregnant mothers. Proper counseling on infant feeding was not done to HIV positive mothers. Hospital staffs were not aware of international code of Breast Milk Substitutes (BMS). BMS were abundantly available in the pharmacies around the hospital and in the market. Some of the BMS products were found violating the International Code of Breast Milk Substitutes. (11)

There could be many reasons for not fulfilling the ten steps of BFHI by hospitals in Nepal. The main reason could be lack of monitoring and supervision activities since a long time, from the time the hospitals were certified. Transfer of almost all the trained staffs and lack of training to the new ones could be the other reason. Reluctance of the hospital administration and concerned government authority and less priority on breastfeeding could be the other possible reasons.

\section{Conclusion}

At present, Child Health Division, DoHS is in the process of finalization the strategy on Infant and Young Child Feeding. Although nutrition section of the division has some programs on breastfeeding it is not enough to promote breastfeeding as desired because the programs are limited only to creating awareness and most of the times they are limited to breastfeeding week (August 1-7) only.

The report of the BFHI assessment clearly indicates breastfeeding promotion has been given less priority even in the tertiary health care setting and there is no any action to control and regulate breast milk substitutes which are found everywhere and the producers and distributors are found violating the Breast Milk Substitute Act. In this context, in order to address one of the important causes of neonatal death, promotion of breastfeeding (early initiation and exclusive breastfeeding) also identified by Lancet as one of the 45 evidence based interventions, is crucial in health care setting as well as in the case of home setting. Child health division must run the programs not only to make aware but also to empower mothers to breastfeed their babies by creating conducive environment for breastfeeding even in work place setting in order to preserve the right of every newborn to get their natural and the best food 'breast milk'. Regular monitoring of BFHI activities is required in health care setting and it should be incorporated in the national health programs.

\section{References}

1. Breastfeeding: foundations for a healthy future. UNICEF, Division of Communication. New York, USA. August 1999

2. Ezine @rticles [Homepage on the Internet] Available from: http:/ /ezinearticles.com/?History-of-Breast-Milk-Substitutes-andHow-They-Came-About\&id=4615867

3. US Department of Health and Human Services. [Homepage on the Internet]. Available from: http://www.ahrq.gov/clinic/tp/ brfouttp.htm.

4. Frank R. Greer, MD, Scott H. Sicherer, MD, A. Wesley Burks, $\mathrm{MD}$, and the Committee on Nutrition and Section on Allergy and Immunology. Official Journal of the American Academy of Padiatrics. Available from: http://pediatrics.aappublications.org/ cgi/content/abstract/121/1/183

5. Todd A. Mahr, MD. Official Journal of the American Academy of Pediatrics. Available from: http://pediatrics.aappublications.org/ cgi/content/abstract/122/Supplement_4/S176?ct=ct

6. Ikechukwu UO, Wilfried K,Syed HA, Ramesh JK,Susan E. Thorax An international Journal of Respiratory Medicine. Thorax doi:10.1136/thx.2008.101543.

Available from: http://thorax.bmj.com/cgi/content/abstract/ thx.2008.101543v1?ct=ct

7. UNICEF/WHO. Baby Friendly Hospital Initiative, revised, updated and expanded for integrated care, Section 5, External Assessment and Reassessment, 2009.

8. Innoncenti Declaration 2005 on Infant and Young Child Feeding. 22 November 2005, Florence, Italy.

9. The Lancet series on nutrition. Series 3, Published Online January 17, 2008. DOI:10.1016/S0140-6736(07)61693-6

10. Unicef.com. [Homepage on the Internet]. Available from:http:/ /www.unicef.org/programme/breastfeeding/baby.htm.

11. Shrestha PS et al. Assessment and Strengthening the Implementation of the Code on Breast Milk Substitutes and the Baby Friendly Hospital Initiative (BFHI), 2011. Child Health Division, MoHP.

12. Nepal Demographic and Health Survey, Kathmandu, Nepal: Ministry of Health and Population, New ERA and Macro International Inc, 2006

13. Nepal Demographic and Health Survey, Kathmandu, Nepal: Ministry of Health and Population, New ERA and Macro International Inc, 2011. 